\title{
Non-Invasive Ventilation in the Treatment of Sleep-Related Breathing Disorders: Concise Clinical Review
}

\author{
${ }^{1}$ Respiratory Diseases Unit, Hospital of Sestri Levante, Italy \\ ${ }^{2}$ Neuromuscular Diseases Unit, Don Gnocchi Foundation, Milan, Italy \\ ${ }^{3}$ Forensic Medicine, ASL4 Chiavarese, Chiavari, Italy \\ ${ }^{4}$ Emergency Department, ASL4 Chiavarese, Chiavari, Italy \\ ${ }^{5}$ Rehabilitation Department, ASL4 Chiavarese, Chiavari, Italy
}

Nicolini Antonello ${ }^{1 *}$, Banfi Paolo², Barlascini Cornelius ${ }^{3}$, Ferraioli Gianluca ${ }^{4}$, Lax Agata ${ }^{2}$ and Grecchi Bruna ${ }^{5}$

\begin{abstract}
Non-invasive mechanical ventilation (NIV) was originally used in patients with acute respiratory compromises or exacerbations of chronic respiratory diseases, as an alternative to the endotracheal tube. Over the last thirty years NPPV has been also used during the night in patients with stable chronic lung disease such as obstructive sleep apnea, the overlap syndrome (COPD and obstructive sleep apnea), neuromuscular disorders, obesity-hypoventilation syndrome, and in other conditions such as sleep disorders associated with congestive heart failure (Cheyne-Stokes respiration). In this review we discuss the different types of NPPV, the specific conditions in which they can be used and the indications, recommendations and evidence supporting the efficacy of NIV. Obstructive sleep apnea syndrome (OSA) is characterized commonly by instability of upper airway during sleep, reduction or elimination of airflow, daytime hypersomnolence, sleep disruption. It is a risk factor for cardiovascular and cerebrovascular disorders including hypertension, myocardial infarction and stroke. Optimizing patient acceptance and adherence to non-invasive ventilation treatment is challenging. The treatment of sleep-related disorders is a life-threatening condition. The optimal level of treatment should be determinate in a sleep laboratory. Side effects directly affecting the patient's adherence to treatment are known. The most common are nasopharyngeal symptoms including increased congestion and rhinorrhea; these effects are related to reduced humidity of inspired gas. Humidification of delivered gas may improve these symptoms. Sleep specialists should review the results of objective testing with the patient. Education of the patient concerning the nature of the disorder and treatment options is important. General education on the impact of weight loss, sleep position, alcohol avoidance, risk factor modification and medication effects should be discussed. The patient should be counseled on the risks and management of drowsy driving. Patient education should optimally be delivered as a part of a multidisciplinary chronic disease management team.
\end{abstract}

Keywords: Sleep-related respiratory disorders; Non-invasive ventilation; Continuous positive airway pressure; Bilevel positive airway pressure

\section{Introduction}

Noninvasive mechanical ventilation (NIV) was originally used in patients with acute respiratory compromises or exacerbations of chronic respiratory diseases, as an alternative to the endotracheal tube. Over the last thirty years NIV has been also used during the night in patients with stable chronic lung disease such as obstructive sleep apnea, the overlap syndrome (COPD and obstructive sleep apnea), neuromuscular disorders, obesity-hypoventilation syndrome, and in other conditions such as sleep disorders associated with congestive heart failure (Cheyne-Stokes respiration) [1]. In this review we discuss the different types of NIV, the specific conditions in which they can be used and the indications, recommendations and evidence supporting the efficacy of NIV.

\section{Specific Conditions for Non-Invasive Ventilation}

\section{Obstructive sleep apnea-hypopnea syndrome (OSA)}

The obstructive apnea-hypopnea syndrome has an incidence of $2 \%$ in women and $4 \%$ in men. It is characterized by recurrent episodes of partial (hypopnea) or complete (apnea), obstruction of the upper airway during sleep, and is associated with episodes of arousal and/or oxyhemoglobin desaturation $[2,3]$.

Symptoms of the syndrome are reported in Table 1.

The pathophysiology of obstructive sleep apnea is still controversial.
Obesity, the classic hallmark in OSA, is not well understood as a cause leading to obstruction of the upper airways. Possible hypotheses include adipose tissue infarction of the tongue and/or the dilator muscles of the pharynx. The upper airway becomes less efficient, reducing oropharyngeal space especially at the end of exhalation. As a result, at the beginning of the next inspiration the dilator muscles of the pharynx (see genioglossus) should produce a greater contraction to

\begin{tabular}{|l|}
\hline Snore \\
\hline Nocturia \\
\hline Unrefreshing sleep \\
\hline Choking \\
\hline Daytime sleepiness \\
\hline Decreased libido \\
\hline Morning headache \\
\hline Enuresis \\
\hline
\end{tabular}

Table 1: Typical symptoms of osas.

*Corresponding author: Nicolini Antonello, Respiratory Diseases Unit, Hospital of Sestri Levante, Via Terzi 43, 16039 Sestri Levante, Italy, Tel: 0185-329145; Fax: 0185329935; E-mail: antonello.nicolini@fastwebnet.it

Received April 30, 2013; Accepted June 10, 2013; Published June 15, 2013

Citation: Antonello N, Paolo B, Cornelius B, Gianluca F, Agata L, et al. (2013) Non-Invasive Ventilation in the Treatment of Sleep-Related Breathing Disorders: Concise Clinical Review. J Gen Pract 1: 110. doi: 10.4172/2329-9126.1000110

Copyright: (c) 2013 Antonello N, et al. This is an open-access article distributed under the terms of the Creative Commons Attribution License, which permits unrestricted use, distribution, and reproduction in any medium, provided the original author and source are credited. 
overcome the tendency of the pharyngeal wall to collapse (due to the negative pressure inside the cavity and pharynx). The supine position is dangerous obstruction as the tongue tends and occludes the rear wall of the oropharynx.

This syndrome has been associated with the development of hypertension, coronary artery disease, bleeding disorders, stroke and increased risk of sudden death during sleep. It is also associated with a higher rate and greater severity of traffic accidents, increased use of health care facilities and reduced capacity for work [4]. Strong evidence exists that non-invasive ventilation, most often, continuous airway positive pressure (CPAP) has significant advantages in this type of disease, improving sleep quality, daytime wakefulness, and cognitive function. Consequently, the quality of life improves. These improvements are wide-ranging: reduction of traffic accidents, lower arterial blood pressure and reduction in the morbidity and mortality rates of myocardial infarction and stroke demonstrate the wide spectrum of CPAP's benefits $[2,5]$.

\section{Complex sleep apnea}

We use the term "Complex Sleep Apnea" (ComplSA) to indicate a condition initially diagnosed as OSA, but characterized, during the application of CPAP, by the absence of respiratory symptoms of obstructive and central apnea by the appearance of frequent or periodic breathing of the Cheyne-Stokes type. Patients are usually older and have a higher frequency of ischemic heart disease as well as an increased fragmentation of sleep that is also "lighter". These characteristics are associated with an increased frequency of central apnea and periodic breathing. The restoration of patency of the upper airway due to the application of CPAP and deregulation or delayed adaptation of the control of the ventilation linked to fluctuations of $\mathrm{PCO}_{2}$ can be a key pathophysiological mechanism of the syndrome [3].

\section{Sleep-disturbances associated with cardiac dysfunction}

The prevalence of obstructive sleep apnea in patients with impaired left ventricular ejection fraction is estimated about $11 \%$ to $53 \%$. It is also known that the sleep obstructive apnea-hypopnea syndrome can worsen a state of congestive heart failure, by causing a periodic increase in negative intrathoracic pressure, by raising arterial blood pressure, and causing tachycardia from sympathetic nervous system stimulation from hypoxia, hypercapnia and arousals [6].

CPAP treatment produces a reduction in blood pressure and improves left ventricular systolic function in patients with chronic heart failure and obstructive sleep apnea. Recent studies in patients with chronic heart failure associated with obstructive sleep apnea have shown a further improvement of cardiac function in patients treated with bilevel positive airway pressure ventilation (BIPAP) [7].

The periodic breathing, Cheyne-Stokes respiration is a particular variety of central sleep apnea which is frequently associated with congestive heart failure.

Central Sleep Apnea (CSA) is associated with periodic breathing. Cheyne-Stokes breathing in heart failure is often the initial factor that, through mechanisms such as high chemo-sensitivity and prolonged circulation time, determines the onset of apnea. CSA with its characteristic desaturation apnea-relate and sympathetic hyperactivity tends to worsen the prognosis of heart failure. CSA is characterized by cessation of respiratory drive during sleep, cessation of airflow obstruction and impaired gas exchange. Unlike the OSA in which there is a respiratory effort to overcome the resistance of the upper airway,
CSA is characterized by the absence of respiratory movement due to the cessation of ventilation. In the heart failure patients, the onset of apnea occurs by a redistribution of blood volume from the lower limbs to pulmonary circulation that is mainly triggered by the supine position. Stimulation of pulmonary vagal receptors causes hyperventilation which results in hypocapnia.

When the value decreases below the hypocapnic apneic threshold, stimulation of the bulbar center ceases, inspiratory drive stops, and apnea occurs. In patients with chronic heart failure, the prolonged circulation time due to the reduction in cardiac output leads to a delay of feedback between chemoreceptors and bulbar centers resulting in hyperventilation and respiratory greater instability. The main risk factors for CSA are male sex, hypocapnia, atrial fibrillation and advanced age. CPAP and BIPAP can fail to correct this category of apneas; therefore, a servo-assisted mode (ASV or adaptive servo ventilation) is recommended [8].

\section{Obesity-Hypoventilation Syndrome}

Obesity hypoventilation refers to a syndrome including daytime hypercapnia $\left(\mathrm{PCO}_{2}>45 \mathrm{mmHg}\right.$ ) in obese people in which no other cause of hypoventilation is present. Its prevalence among patients with obstructive sleep apnea is $20 \%$ to $30 \%$ and is greater in extremely obese patients (BMI $>40$ ). Approximately $10 \%$ of patients with obesityhypoventilation syndrome do nothave sleep apnea-hypopnea syndrome. Additionally, nocturnal hypoxemia and diurnal hypercapnia persist in about $40 \%$ of these patients after the treatment with CPAP eliminated apnea. Factors other than sleep apnea contribute to the development of obesity-hypoventilation syndrome associated with the persistence of daytime hypercapnia: these include body mass index and apneahypopnea index, mean overnight oxygen saturation and the severity of restrictive ventilatory syndrome. BIPAP therapy may be useful in those patients in whom CPAP has failed or gave unsatisfactory results. The average volume-assured pressure support ventilation seems to be able to lower $\mathrm{PCO}_{2}$ in a superior manner compared to BIPAP, but it is not able to further improve the oxygenation, sleep quality or quality of life [9].

\section{Neuromuscular and Chest Wall Disorders}

Non-invasive ventilation has been used in patients with progressive neuromuscular disease or serious abnormalities of the thoracic cage, with recognized benefits, including an improved survival rate and an improved quality of life. The benefits of non-invasive ventilation in this type of patient includes improvements o daytime levels of blood gas (including hypercapnia), a reduction in the oxygen cost of breathing, an increase in the ventilatory response to increased carbon dioxide, and improved lung compliance [10].

\section{Chronic Obstructive Pulmonary Disease and Sleep Apnea (Overlap Syndrome)}

Sleep-disordered breathing (mainly obstructive sleep apnea) and chronic obstructive pulmonary disease (COPD) are the most common lung diseases: a large number of patients have both disorders, hence the term "overlap syndrome." The overlap syndrome was first described by Flenley in 1985 as a combination of COPD and obstructive apneahypopnea syndrome. The coexistence of these conditions can lead to severe episodes of desaturation during sleep, thus increasing the risk of hypoxemia, daytime hypercapnia and pulmonary hypertension. Noninvasive ventilation may be useful in patients with overlap syndrome, but there are no controlled studies [11,12]. 


\section{Clinical Criteria for Initiating Non-Invasive Ventilation}

The presence of symptoms and physiological markers of hypoventilation are useful in identifying the clinical severity; moreover, these factors relate to therapeutic decision-making, especially initiating nocturnal non-invasive ventilation) [1]. In a typical "progressive disease" two successive steps occur:

1) Initial phase of nocturnal hypoventilation reversible during waking hours, associated with few or no clinical symptoms.

2) Nocturnal and daylight hypoventilation associated with clinical symptoms which shows a reduced respiratory reserve.

The continuous sleep monitoring of $\mathrm{pCO}_{2}$ and $\mathrm{O}_{2}$ saturation values are necessary to document the presence of nocturnal hypoventilation which may be present in all the stages of sleep (in some cases only during REM sleep). Daytime hypoventilation is defined by reduced values of arterial oxygen tension $\left(\mathrm{PaO}_{2}\right)$, high levels of arterial carbon dioxide tension $\left(\mathrm{PaCO}_{2}\right)$ and/or high serum bicarbonate levels with a relatively normal $\mathrm{pH}$. Chronic daytime hypoventilation is an important indicator always associated with nocturnal hypoventilation. In the presence of daytime hypoventilation, polysomnography is done to exclude obstructive or central apnea. Clinical symptoms, although modest, should be evaluated carefully, because they are very important determining disease severity and prognosis as well defining the need for non- invasive ventilation. Pulmonary function tests may be helpful in defining the reduction of lung function, but they have a low predictive value for patients with sleep-related hypoventilation. However, in patients with neuromuscular disease, there is a good correlation between lung function and nocturnal hypoventilation: it has been shown that hypoventilation during REM only or during all sleep stages or in the daytime, appears respectively with supine inspiratory vital capacities of less than $40 \%, 25 \%$ or $12 \%$ of predicted values $[1,13]$.

\section{Types of Non-Invasive Ventilation}

\section{CPAP (continuous positive airway pressure)}

CPAP is currently the most widely used mode of non-invasive ventilation in the treatment of obstructive sleep-disordered breathing and of disordered breathing associated with chronic heart failure. It consists in the application of a constant level of positive pressure during spontaneous breathing. The mechanism of action of CPAP includes a series of actions on pathophysiological mechanisms:

a) It prevents intermittent narrowing and collapse of the airways in patients with obstructive sleep apnea-hypopnea syndrome.

b) It counteracts auto-positive end-expiratory pressure, which reduces respiratory muscles load, the work of breathing and daytime $\mathrm{PaCO}_{2}$ in patients with overlap syndrome.

c) It improves lung function, particularly the functional residual capacity, daytime gas exchange in patients with obstructive sleep apnea-hypopnea syndrome.

d) It improves systolic function of the left ventricle in patients with heart failure coexisting with obstructive sleep apnea-hypopnea syndrome [2].

\section{Auto-CPAP (automatic adjustment of the level of continuous positive airway pressure)}

Auto-CPAP (APAP) is delivered via a self-titrating CPAP device, which uses algorithms to detect variations in the degree of obstruction and adjusts the pressure level to restore normal breathing. Auto-CPAP compensates for factors that modify the upper airway collapsibility, such as body posture during sleep, stage of sleep, use of alcohol, and drugs that affect upper airway muscle tone [2]. It is not recommended in the diagnosis of OSA and titrating continuous pressure during split-night. The auto-CPAP can be used during polysomnography or cardiorespiratory monitoring to titrate a single pressure value to be used later with fixed CPAP for treatment of OSA in patients without comorbid conditions. The use of auto-CPAP is reserved only for those patients with sleep apnea syndrome only present during REM or respiratory events related to position, in whom constraining positional maneuvers are poorly tolerated [14].

\section{Servo-assisted ventilation (ASV-adaptive servo-ventilation)}

The servo-assisted ventilation (ASV) has been developed for the treatment of Cheyne-Stokes respiration-central apnea syndrome in patients with chronic heart failure who have a breathing pattern characterized by periods of crescendo-decrescendo change in tidal volume with possible intercalated episodes of central apnea or hypopnea. This more complex device can use patient expiratory positive airway pressure (EPAP) level sufficient to control the obstructive apnea. The device then automatically adjusts the inspiratory pressure support for each inspiration within a prespecified range, to maintain a movingtarget ventilation set at $90 \%$ of the patient's recent average ventilation. The aim is the stabilization of breathing patterns and to reduce the respiratory alkalosis that can trigger apnea reentry cycles [15].

\section{BIPAP (Bilevel positive airway pressure)}

Bilevel positive airway pressure (BIPAP) is also used for sleeprelated disorders (including those associated with chronic heart failure), but its main indication is in pathological conditions associated with hypoventilation. The BIPAP devices deliver a higher pressure during inspiration (IPAP - inspiratory positive airway pressure) and a lower pressure during expiration (EPAP-expiratory positive airway pressure). The gradient between IPAP and EPAP (pressure support ventilation) is crucial in maintaining adequate alveolar ventilation and reducing $\mathrm{PCO}_{2}$. The IPAP acts also in reducing the work of breathing and fatigue, reducing the workload of respiratory muscles; EPAP has the function of maintaining the patency of the upper airway, to control obstructive apnea and to improve the functional residual capacity. BIPAP is now proposed for the type of patients who require high expiratory pressures to control obstructive sleep apnea-hypopnea, but who cannot tolerate exhaling against a high-fixed CPAP pressure [17]. Other indications of BIPAP are the treatment of coexisting central apnea or hypoventilation, the obesity-hypoventilation syndrome that cannot have a complete correction of the hypoxic state with only CPAP, the overlap syndrome and neuromuscular disorders. Although the patient should be able to maintain spontaneous breathing, it is used to set a back-up rate option for those patients whose ventilation during sleep may be particularly impaired (neuromuscular disorders, complex sleep apnea, central apnea in chronic heart failure, obesityhypoventilation syndrome) $[2,16]$.

\section{Average volume-assured pressure support ventilation (AVAPS)}

Average volume-assured pressure support ventilation (AVAPS) is used in patients with chronic hypoventilation and in particular with obesity hypoventilation syndrome, neuromuscular diseases, and sometimes, in chronic obstructive pulmonary disease. In this mode a target tidal volume is set; the device adjusts the pressure support which 
to reach that set tidal volume. The advantage of this mode (a cross between the volume and pressure-assisted mode) is that it guarantees a delivered tidal volume adjusted despite variability in the patient effort, airway resistance, and lung or chest wall compliance. A particular benefit of this mode is that it may be modified as the disease progresses, (as it occurs in neuromuscular disorders such as amyotrophic lateral sclerosis) [2]. All the types of ventilation are summarized in the Table 2.

\section{Management of NIV}

\section{Initiation and settings in case of nocturnal ventilation}

The main objective of the use of non-invasive ventilation is the correction of blood gas values near "normal" with the least possible discomfort or sleep disturbance. Even if there is no absolute recommendation, it is good practice to proceed in three successive steps. The first step is to choose and adjust the ventilator settings while the patient is awake, assuring physiological adequacy and patient comfort for at least one or two hours. In the second step the clinician should evaluate the adequacy of the settings when sleeping during a nap and a night's sleep. Different options, according to the resources available in each center, are used. A full polysomnography recording oxygen saturation $\left(\mathrm{SpO}_{2}\right)$ and transcutaneous $\mathrm{PCO}_{2}\left(\mathrm{PtcCO}_{2}\right)$ or end-tidal $\left(\mathrm{PetCO}_{2}\right)$, flow, tidal volume, airway pressure, rib cage and abdomen excursion as well as sleep- staging allows a complete assessment (gold standard). When the resources are not available fewer parameters may be used. The minimum required is recording $\mathrm{SpO}_{2}$ on room air, assessing that the normalization of $\mathrm{SpO}_{2}$ accompanies the normalization, or at least the improvement in $\mathrm{PaCO}_{2}$.
The second step relates to patient tolerance, comfort, changes in sleep quality and well-being; these data should be obtained. The third step consists of looking for reduction in $\mathrm{PaCO}_{2}$ and augmentation of $\mathrm{PaO}_{2}$ without dyspnea during the day in free ventilation after several nights of NIV. This is done to confirm that the settings are adequate for the patient's needs $[1,17]$.

If the results are not satisfactory, changes must be made to the settings. One may also change the type of mask and ventilator. At the beginning a starting level of pressure support of $10 \mathrm{~cm} \mathrm{H} \mathrm{H}_{2} \mathrm{O}$ is recommended. Continuing the adaptation, the pressure level can progressively be increased to achieve evidence of improvement. Pressure support higher than $20 \mathrm{~cm} \mathrm{H}_{2} \mathrm{O}$ is rarely necessary $[1,17,18]$. A back-up frequency set close to the spontaneous frequency of the patient during sleep is reasonable substitute to inspiratory trigger failure to avoid central apnea induced by transitory but repeated hyperventilation passing the apnea threshold. When employing a volume-preset ventilator, the initial suggested setting may be established by adjusting the frequency of ventilator-delivered breaths so that it approximates the patient's spontaneous breathing frequency during sleep, an inspiratory time/total breathing time between 0.33 and 0.5 and a relatively high tidal volume of around $10-15 \mathrm{ml} / \mathrm{kg}$ to insure sufficient tidal volume in case of leaks [1].

Supplemental oxygen $\left(\mathrm{O}_{2}\right)$ will be added to the ventilator circuit, immediately near the interface or hooked to a ventilator, especially in those patients who require oxygen during the daytime (COPD, cystic fibrosis, bronchiectasis). In the absence of obstructive pulmonary disease, the addition of $\mathrm{O}_{2}$ to the ventilation circuit may be justified

\begin{tabular}{|c|c|c|c|c|}
\hline Type & Applications & Setup requirements & Advantages & Disadvantages \\
\hline $\begin{array}{l}\text { Continuous positive } \\
\text { airway pressure (CPAP) }\end{array}$ & $\begin{array}{l}\text { Obstructive sleep apnea; congestive } \\
\text { heart failure with coexisting obstructive } \\
\text { sleep apnea; obesity-hypoventilation } \\
\text { syndrome with coexisting obstructive } \\
\text { sleep apnea }\end{array}$ & CPAP level & Simple to use; relatively inexpensive & $\begin{array}{l}\text { Minimal or no ventilation support; } \\
\text { preset pressures may not } \\
\text { address variability in obstructive } \\
\text { sleep apnea, severity with sleep } \\
\text { stages and positional stages }\end{array}$ \\
\hline AUTO-CPAP & $\begin{array}{l}\text { Obstructive sleep apnea; congestive } \\
\text { heart failure with coexisting obstructive } \\
\text { sleep apnea; obesity-hypoventilation } \\
\text { syndrome with coexisting obstructive } \\
\text { sleep apnea }\end{array}$ & $\begin{array}{l}\text { Range of allowable } \\
\text { CPAP levels }\end{array}$ & $\begin{array}{l}\text { Reduces number of titration } \\
\text { studies; self-adjusting to adapt to } \\
\text { variability in obstructive sleep apnea } \\
\text { with sleep stages and positional } \\
\text { changes; maybe useful for patients } \\
\text { with ongoing weight loss such as } \\
\text { after bariatric surgery }\end{array}$ & $\begin{array}{l}\text { More expensive than fixed CPAP; } \\
\text { may not be effective for patients } \\
\text { with cardiopulmonary disorders } \\
\text { or other conditions in which } \\
\text { desaturation may be unrelated to } \\
\text { obstructive events }\end{array}$ \\
\hline $\begin{array}{l}\text { Adaptive servo-ventilation } \\
\text { (ASV) }\end{array}$ & $\begin{array}{l}\text { Congestive heart failure; central sleep } \\
\text { apnea; complex sleep apnea syndrome }\end{array}$ & $\begin{array}{l}\text { Maximum and minimum } \\
\text { inspiratory pressures; } \\
\text { end-expiratory pressure }\end{array}$ & $\begin{array}{l}\text { Adapts pressure to maintain more } \\
\text { consistency of respiration over time }\end{array}$ & $\begin{array}{l}\text { More expensive than other } \\
\text { modes; may worsen ventilation } \\
\text { in disease with chronic ventilator } \\
\text { insufficiency such as COPD or } \\
\text { restrictive thoracic disorders }\end{array}$ \\
\hline $\begin{array}{l}\text { Bilevel positive airway } \\
\text { pressure (BIPAP) without } \\
\text { backup rate }\end{array}$ & $\begin{array}{l}\text { Obstructive sleep apnea with CPAP } \\
\text { intolerance; obstructive sleep apnea } \\
\text { with central sleep apnea; restrictive } \\
\text { thoracic disorders; severe chronic } \\
\text { obstructive pulmonary disease; obesity } \\
\text { hypoventilation syndrome with coexisting } \\
\text { obstructive sleep apnea and residual } \\
\text { hypoventilation despite CPAP }\end{array}$ & $\begin{array}{l}\text { Inspiratory and expiratory } \\
\text { positive airway pressures }\end{array}$ & $\begin{array}{l}\text { Promotes alveolar ventilation; } \\
\text { unloads respiratory muscles; } \\
\text { decreases the work of breathing; } \\
\text { controls obstructive hypopneas }\end{array}$ & $\begin{array}{l}\text { More expensive than CPAP; may } \\
\text { generate central apnea }\end{array}$ \\
\hline $\begin{array}{l}\text { Bilevel positive airway } \\
\text { pressure (BIPAP) with } \\
\text { backup rate }\end{array}$ & $\begin{array}{l}\text { Central sleep apnea; complex sleep } \\
\text { apnea syndrome; worsening restrictive } \\
\text { disorder }\end{array}$ & $\begin{array}{l}\text { Inspiratory and expiratory } \\
\text { positive airway pressure; } \\
\text { backup rate; ratio of } \\
\text { inspiratory time to } \\
\text { expiratory time }\end{array}$ & $\begin{array}{l}\text { Provides mandatory respiratory } \\
\text { support during central or } \\
\text { pseudocentral apneas }\end{array}$ & $\begin{array}{l}\text { More expensive than } \\
\text { conventional BIPAP; may } \\
\text { generate central apnea }\end{array}$ \\
\hline $\begin{array}{l}\text { Average volume-assured } \\
\text { pressure support (AVAPS) }\end{array}$ & $\begin{array}{l}\text { Obesity-hypoventilation syndrome; } \\
\text { neuromuscular disease; chronic } \\
\text { obstructive pulmonary disease }\end{array}$ & $\begin{array}{l}\text { Target tidal volume (8 } \\
\mathrm{ml} / \mathrm{Kg} \text { of ideal weight); } \\
\text { inspiratory positive } \\
\text { airway pressure limits; } \\
\text { respiratory rate }\end{array}$ & $\begin{array}{l}\text { Ensures a delivered tidal volume; } \\
\text { compensates for diseases } \\
\text { progression }\end{array}$ & $\begin{array}{l}\text { More expensive than other } \\
\text { modes }\end{array}$ \\
\hline
\end{tabular}

Table 2: Types of Non-ilnvasive ventilation. 
only to maintain an acceptable level of $\mathrm{PaO}_{2}$ during sleep and only after all the parameters have been optimized [19].

\section{Follow-up}

Clinical follow-up and daytime arterial blood gases should be conducted at least twice a year. The recordings during sleep, (possibly identical to those performed for the adaptation to non-invasive ventilation), are useful. At any time, when there are indications of unsatisfactory results such as the recurrence of clinical symptoms and/ or signs of hypoventilation on arterial blood gases, inadequate noninvasive ventilation should be suspected, and a complete objective assessment of ventilation during sleep with polysomnography must be undertaken

When the non-invasive ventilation is not proven to be optimal, a change of ventilation modality and/or parameters of the ventilator and/or a revision of the interface may be indicated. In case of disease progression one should be considered increasing the duration of ventilation during the day. The interfaces need to be regularly checked and modified or adapted to changing needs of the patient [1].

\section{Management of Complications and Side Effects}

\section{Air leaks during ventilation}

The major potential adverse effect is the loss of effectiveness of the ventilation and therefore the potential fragmentation of sleep. A variety of more or less effective measures have been suggested to tackle the problem of leaks during NIV. These include the prevention of neck flexion, the semi-recumbent positioning of the patient, the use of a chin rest or a cervical collar to prevent opening of the mouth, switching to controlled pressure mode, decreasing the peak inspiratory pressure and increasing the delivered volume, optimizing the interface (using oro-nasal masks if possible). The effectiveness of each of these measures must be confirmed during sleep recording [20].

\section{Nasal dryness, congestion}

As shown in the CPAP literature, the side effects of nasal dryness, congestion, and rhinitis are related to a defect of humidification. For the patients with nasal and mouth dryness, a cold pass over or a heated humidifier can be used [21,22].

\section{Aerophagia}

Aerophagia (swallowing air) is frequently reported but is rarely intolerable. Minor clinical signs are eructation, flatulence and abdominal discomfort. Aerophagia usually depends on the level of

\begin{tabular}{|l|l|}
\hline Complication and/or side effect & Action \\
\hline Air Leaks & Prevention of neck flexion \\
\hline & Semi-recumbent positioning \\
\hline & Use of chin rest \\
\hline & Use of cervical collar \\
\hline & Switch to controlled pressure mode \\
\hline & $\begin{array}{l}\text { Decrease peak inspiratory pressure and } \\
\text { increase volume }\end{array}$ \\
\hline Nasal Dryness,Congestion & Optimize the interfaces(using oro-nasal mask) \\
\hline & Cold pass over \\
\hline Aerofagia,Eructation,Flatulence, & Heated humidifier \\
\hline Abdominal Discomfort & $\begin{array}{l}\text { Decrease peak inspiratory pressure below } \\
25 \mathrm{~cm}_{2} \mathrm{O}\end{array}$ \\
\hline
\end{tabular}

Table 3: Management of complications and side effects of NIV. inspiratory pressure and decreases if the peak inspiratory pressure is maintained below $25 \mathrm{~cm} \mathrm{H}_{2} \mathrm{O}$ pressure [22] (Table 3).

\section{Conclusions}

1. Optimizing patient acceptance and adherence tonon-invasive ventilation treatment is challenging. The treatment of sleeprelated disorders is a life-threatening condition. The optimal level of treatment should be determined in a sleep laboratory.

2. Side effects directly affecting the patient's adherence to treatment are known. The most common are nasopharyngeal symptoms including increased congestion and rhinorrhea; these effects are related to reduce humidity of inspired gas. Humidification of delivered gas may improve these symptoms. Sleep specialists should review the results of objective testing with the patient. Education of the patient concerning the nature of the disorder and treatment options is mandatory.

3. The impact of weight loss, sleep position, alcohol avoidance, and risk factor modification and medication effects should be discussed. The patient should be counseled on the risks and management of drowsy driving. Patient education should optimally be delivered as a part of a multidisciplinary chronic disease management team.

\section{Acknowledgments}

The authors thank Dr. Simona Colamartino for the help in conception and revision of the manuscript.

\section{References}

1. Robert D, Argaud L (2007) Non-invasive positive ventilation in the treatment of sleep-related breathing disorders. Sleep Med 8: 441-452.

2. Theerakittikul T, Ricaurte B, Aboussouan LS (2010) Noninvasive positive pressure ventilation for stable outpatients: CPAP and beyond. Cleve Clin J Med 77: 705-714.

3. Cassel W, Canisius S, Becker HF, Leistner S, Ploch T, et al. (2011) A prospective polysomnographic study on the evolution of complex sleep apnoea. Eur Respir J 38: 329-337.

4. Patil SP, Schneider H, Schwartz AR, Smith PL (2007) Adult obstructive sleep apnea: pathophysiology and diagnosis. Chest 132: 325-337.

5. Marin JM, Carrizo SJ, Vicente E, Agusti AG (2005) Long-term cardiovascular outcomes in men with obstructive sleep apnoea-hypopnoea with or without treatment with continuous positive airway pressure: an observational study. Lancet 365: 1046-1053.

6. Bordier P (2009) Sleep apnoea in patients with heart failure. Part I: diagnosis definitions, prevalence, pathophysiology and haemodynamic consequences. Arch Cardiovasc Dis 102: 651-661.

7. Mansfield DR, Gollogly NC, Kaye DM, Richardson M, Bergin P, et al. (2004) Controlled trial of continuous positive airway pressure in obstructive sleep apnea and heart failure. Am J Respir Crit Care Med 169: 361-366.

8. Tkacova R, Hall MJ, Liu PP, Fitzgerald FS, Bradley TD (1997) Left ventricular volume in patients with heart failure and Cheyne-Stokes respiration during sleep. Am J Respir Crit Care Med 156: 1549-1555.

9. Mokhlesi B (2010) Obesity hypoventilation syndrome: a state-of-the-art review. Respir Care 55: 1347-1362.

10. Nickol AH, Hart N, Hopkinson NS, Moxham J, Simonds A, et al. (2005) Mechanisms of improvement of respiratory failure in patients with restrictive thoracic disease treated with non-invasive ventilation. Thorax 60: 754-760.

11. Hill NS (2004) Noninvasive ventilation for chronic obstructive pulmonary disease. Respir Care 49: 72-87.

12. McEvoy RD, Pierce RJ, Hillman D (2009) Australian trial of non-invasive ventilation in chronic airflow limitation (AVCAL) Study group. Nocturnal non- 
Citation: Antonello N, Paolo B, Cornelius B, Gianluca F, Agata L, et al. (2013) Non-Invasive Ventilation in the Treatment of Sleep-Related Breathing Disorders: Concise Clinical Review. J Gen Pract 1: 110. doi: 10.4172/2329-9126.1000110

Page 6 of 6

invasive nasal ventilation in stable hypercapnic COPD: a randomized controlled trial. Thorax 64: 561-566.

13. Lo Coco D, Marchese S, Corrao S, Cettina Pesco M, La Bella V, et al. (2006) Development of chronic hypoventilation in amyotrophic lateral sclerosis patients. Respir Med 100: 1028-1036.

14. Meurice JC, Cornette A, Philip-Joet F, Pepin JL, Escourrou P, et al. (2007) Evaluation of autoCPAP devices in home treatment of sleep apnea/hypopnea syndrome. Sleep Med 8: 695-703.

15. Teschler H, Döhring J, Wang YM, Berthon-Jones M (2001) Adaptive pressure support servo-ventilation: a novel treatment for Cheyne-Stokes respiration in heart failure. Am J Respir Crit Care Med 164: 614-619.

16. Kushida CA,Littner MR,Hirshkowitz M.American Academy of Sleep Medicine. Practice parameters for the use of continous and bilevel positive airway pressure devices to treat adult patients with sleep related patients breathing disorders.Sleep 2006;29:375-380

17. Epstein LJ, Kristo D, Strollo PJ Jr, Friedman N, Malhotra A, Patil SP, Ramar
K, Rogers R, Schwab RJ, Weaver EM, Weinstein MD; Adult Obstructive Sleep Apnea Task Force of the American Academy of Sleep Medicine. Clinical Guideline for the Evaluation, Management and Long-term Care of Obstructive Sleep Apnea in Adults.J Clin Sleep Disord 2009;5(3):263-276

18. Rosario IC (2011) Obstructive sleep apnea: a review and update. Minn Med 94: 44-48.

19. Schwartz AR, Kacmarek RM, Hess DR (2004) Factors affecting oxygen delivery with bi-level positive airway pressure. Respir Care 49: 270-275.

20. Teschler H, Stampa J, Ragette R, Konietzko N, Berthon-Jones M (1999) Effect of mouth leak on effectiveness of nasal bilevel ventilatory assistance and sleep architecture. Eur Respir J 14: 1251-1257.

21. Randerath WJ, Meier J, Genger H, Domanski U, Rühle KH (2002) Efficiency of cold passover and heated humidification under continuous positive airway pressure. Eur Respir J 20: 183-186.

22. Hill NS (2000) Complications of noninvasive ventilation. Respir Care 45: 480481. 